\title{
Extension of the reactive power compensation for the pulsed power supply of ASDEX Upgrade
}

\author{
Claus-Peter Käsemann, Igor Goldstein, Christian Jacob, Michael Rott, Michael Schandrul and the \\ ASDEX Upgrade Team
}

Max Planck Institute for Plasma Physics, Boltzmannstraße 2, 85748 Garching, Germany

\begin{abstract}
ASDEX Upgrade (AUG) is an essential element of the European Medium Sized Tokamak (MST) program towards a fusion power plant. It investigates plasma control and performance from plasma core (e.g. current drive and central heating) up to plasma-wall interaction (e.g. plasma confinement and heat exhaust). In order to improve the possibilities and flexibility of the experiment, the heating (ECRH, ICRF and NBI) and power supply systems will be extended and optimized (Käsemann et al., 2017). For plasma ignition and current ramp up of the poloidal field coils high DC voltage is required. During plasma flattop only the ohmic losses of the copper made coils have to be covered. This partial load operation of the high current converters results in high reactive power demand. The power supply of AUG is based on flywheel generators with limited power and energy. To reduce the current load to the generator, a 90 Mvar static reactive power compensation unit has been installed at flywheel generator EZ4 with 2x 15 Mvar and 2x 30 Mvar switched compensation modules.
\end{abstract}

Keywords: ASDEX Upgrade; Flywheel motor generator; Power supply; Reactive power compensation

\section{Introduction}

The ASDEX Upgrade (AUG) experiment has a pulsed nature with a plasma flattop time of maximum $10 \mathrm{~s}$. The complete pulse including ramp up and ramp down of the plasma is about $20 \mathrm{~s}$. The mean repetition rate is about $20 \mathrm{~min}$. Three large flywheel generators supply the high current converters (HC, magnetic confinement) and the high voltage converters (HV, additional heating) with pulsed power up to 571 MVA and stored energies up to $2782 \mathrm{MJ}$ (Fig. 1, [1]).

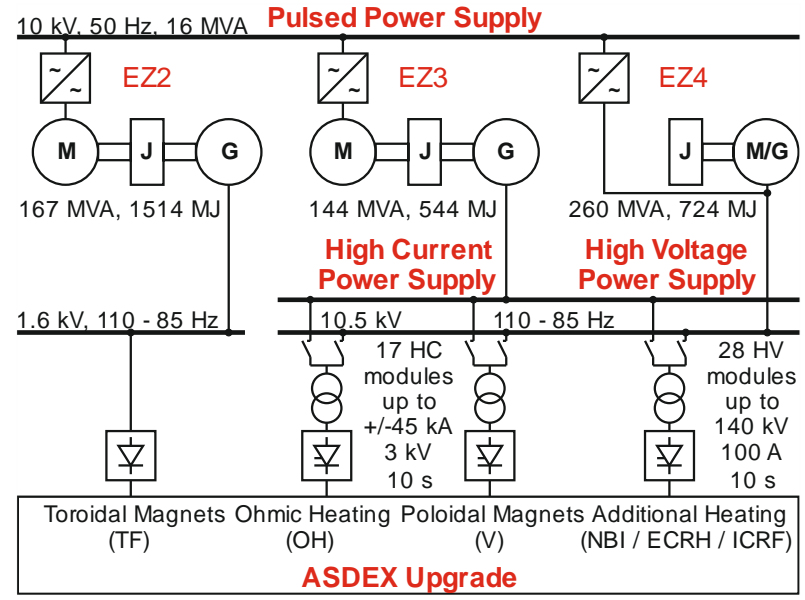

Fig. 1. AUG Pulsed Power Supply Network.

AUG is permanently improving its plasma scenarios and the power supply systems have to meet the progressing and increasing requirements of the research program [2]. Since generator EZ4 reached its $\mathrm{I}^{2} \mathrm{t}$ limit during high power discharges, AUG could not make use of its complete stored energy. Due to the reactive power characteristics of the converters supplying the AUG load pulse it seemed to be obvious to install a static reactive power compensation (RPC) for power factor improvement. Based on the experience with a 120 Mvar RPC with 8x 15 Mvar switching steps at generator EZ3 $[3,4]$, a 90 Mvar compensation for generator EZ4 has been planned, installed, commissioned and is in regular operation since 2017.

\section{Application}

\subsection{Generator operation}

Generator EZ4 has a combined motor/generator with horizontal shaft line assembly and oil lubricated journal bearings. The generator is solid-coupled to the flywheel. The three-phase synchronous machine has eight salientpole rotor windings connected to an excitation converter. The stator is connected to the drive converter and load feeder. The 7.5 MW drive converter operates over the full speed range, start-up included. The output line frequency varies between 85 and $110 \mathrm{~Hz}$, proportional to the generator's speed (1275 to $1650 \mathrm{~min}^{-1}$ ). During a plasma pulse the generator converts the kinetic rotational energy of the flywheel into electrical energy. The power circuit of EZ4 is shown in Fig. 2.

\subsection{Experience with RPC of generator EZ3}

The full voltage of the high current converters is only needed for plasma ignition and current ramp up (dI/dt) in the poloidal field coils. During current flattop the voltage is strongly reduced (ohmic losses, only) by a delay of the thyristor firing angle. This results in a so called phase control reactive power. To reduce the reactive power load and thus the current and $\mathrm{I}^{2} \mathrm{t}$ level of generator EZ3, eight reactive power compensation modules with 15 Mvar each have been installed in 2001. This 
improved the use of the available energy and allowed a longer pulse length.

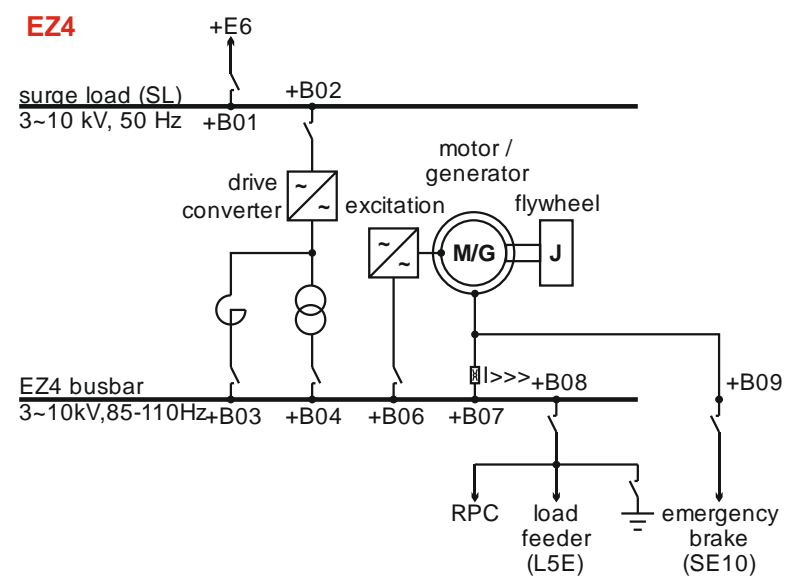

Fig. 2. Single line diagram generator EZ4.

\section{Design studies and simulations}

\subsection{Computer simulations}

Detailed simulations of the generator control system have been performed throughout the whole project to ensure proper behavior of the RPC and system stability. The computer models of the synchronous machine are based on the Park equations and are implemented on the C-interface of ANSYS Simplorer v7. The model is described in detail in [5]. Based on the experience with the existing model of generator EZ3, a new model was built and parameterized for generator EZ4 and steadily improved according to the latest measurement results of commissioning. Most challenging was the identification of the voltage controller.

The Simplorer Model is shown in Fig. 3. The direction of power flow is as follows: flywheel (drive) $\rightarrow$ synchronous machine $\rightarrow$ RPC $\rightarrow$ load. In order to switch an RPC module, the damping resistance is changed from a very high value ("off") to the real value ("on"). The active power $\mathrm{p}(\mathrm{t})$ and the reactive power $\mathrm{q}(\mathrm{t})$ is measured and plotted with reference to the simulated stator voltage and frequency within an electrical network with rapidly changing active and reactive (capacitive or inductive) components. The results are given in Fig. 4.

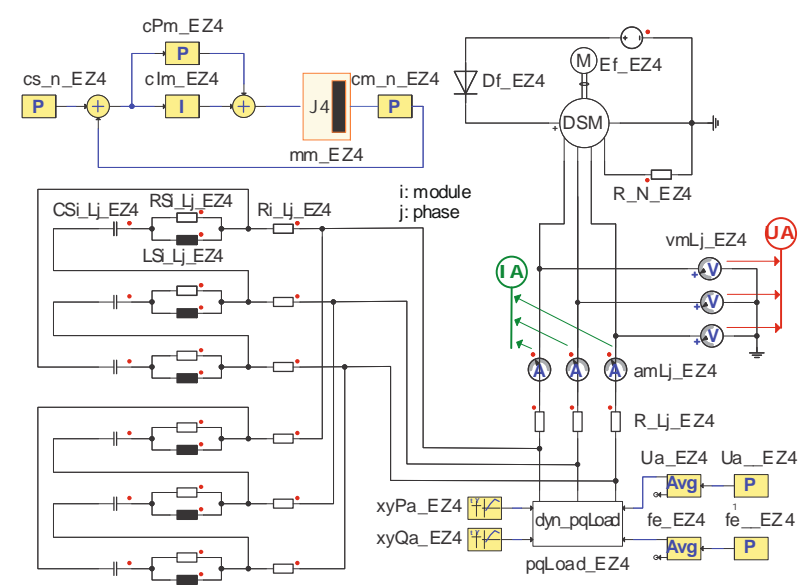

Fig. 3. Simplorer simulation model with two modules.
Switching of the RPC modules is controlled by the actual reactive power $q(\mathrm{t})$. The resulting transients in stator voltage and current as well as the shape of the excitation current and voltage have been examined. The permissible stator power has been checked by scaling the profile of Fig. 4 towards the maximum load limits. Different switching sequences of 15 and 30 Mvar RPC modules have been simulated to find out the smoothest sequence for the installation. Moreover, the effects of non-synchronized switching operations on the synchronous machine and $10 \mathrm{kV}$ network have been assessed. The satisfactory simulation results have been confirmed during commissioning.

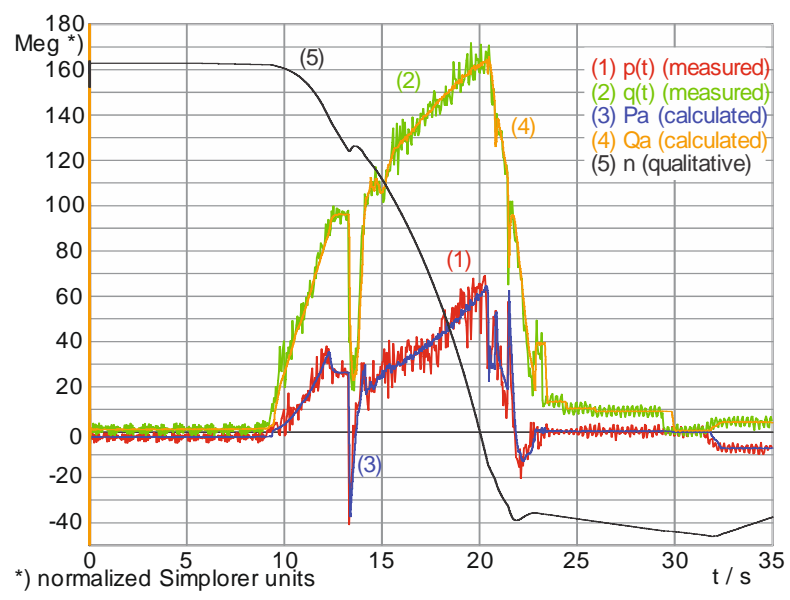

Fig. 4. Simulated versus measured generator control.

\subsection{Switching experiments}

Due to safety reasons (prevent generator overload in case of a sudden RPC tripping) generator EZ3 uses only six out of eight RPC modules. The two remaining RPC modules were connected to generator EZ4 in 2014 in order to prove the system stability of a converter driven and self excited generator. No problems like overvoltages or voltage fluctuations could be observed. Therefore an upgrade to 90 Mvar was scheduled.

\section{RPC design}

\subsection{Overall layout}

Table 1. Distribution of RPC modules.

\begin{tabular}{ccc}
\hline EZ3 & EZ4 & Q Module \\
\hline Module 1 & Module 3 & 15 Mvar \\
Module 2 & Module 4 & 15 Mvar \\
Module 7 (5+7) & Module 5 (new) & 30 Mvar \\
Module 8 (6+8) & Module 6 (new) & 30 Mvar \\
\hline
\end{tabular}

Two main constraints had to be taken into account: limited budget and space. After the successful switching experiments, the decision was taken to reconfigure and extend the existing RPC of EZ3 with 8x 15 Mvar modules as two RPCs with 2x 15 Mvar and 2x 30 Mvar modules for EZ3 and EZ4 each (see Table 1). This means that the total number of switching modules stays the same. No extension of the $10 \mathrm{kV}$ switchgear and of the control units was necessary. With two "small" and two "big" compensation steps, accurate compensation according to the reactive power demand is possible. 


\subsection{Power circuit}

Table 2. Main data of RPC modules.

\begin{tabular}{|c|c|c|c|}
\hline \multicolumn{4}{|l|}{ RPC-module } \\
\hline reactive power & 15 & 30 & Mvar \\
\hline \multicolumn{4}{|l|}{ capacitor bank } \\
\hline capacity & 67,2 & 134,4 & $\mu \mathrm{F}$ \\
\hline \multicolumn{4}{|l|}{ damping reactor } \\
\hline choking factor & 7 & 7 & $\%$ \\
\hline inductivity & 2,7 & 1,35 & $\mathrm{mH}$ \\
\hline filter quality $(380 \mathrm{~Hz})$ & \multicolumn{3}{|c|}{60} \\
\hline nominal current $(100 \mathrm{~Hz})$ & 600 & 1200 & A \\
\hline harmonic current & 200 & 400 & A \\
\hline nominal voltage & \multicolumn{2}{|c|}{12} & $\mathrm{kV}$ \\
\hline operating frequency & \multicolumn{2}{|c|}{$85-110$} & $\mathrm{~Hz}$ \\
\hline \multicolumn{4}{|l|}{ damping resistance } \\
\hline resistance $\left(20^{\circ} \mathrm{C}\right)$ & 70 & 35 & $\Omega$ \\
\hline
\end{tabular}

The power circuit of an RPC module including integration into the generator busbar system is shown in Fig. 5. A second set of current transformers (CT) had to be installed. While the existing measurement records the generator current, the new CT is installed at the load feeder behind the RPC to measure the load current (= generator current + RPC current). In order to protect the generator against possible overvoltages arising from the switching of the capacitors, additional surge arresters have been added to the $10 \mathrm{kV}$ busbar behind the $\mathrm{I}_{\mathrm{S}}$ limiters. The switchboard of an RPC module comprises four cubicles: An upstream 3-phase circuit-breaker (HVCB) cubicle for mainly protection and three single phase HVCB cubicles for the phase-synchronized switching of the three RPC phases.

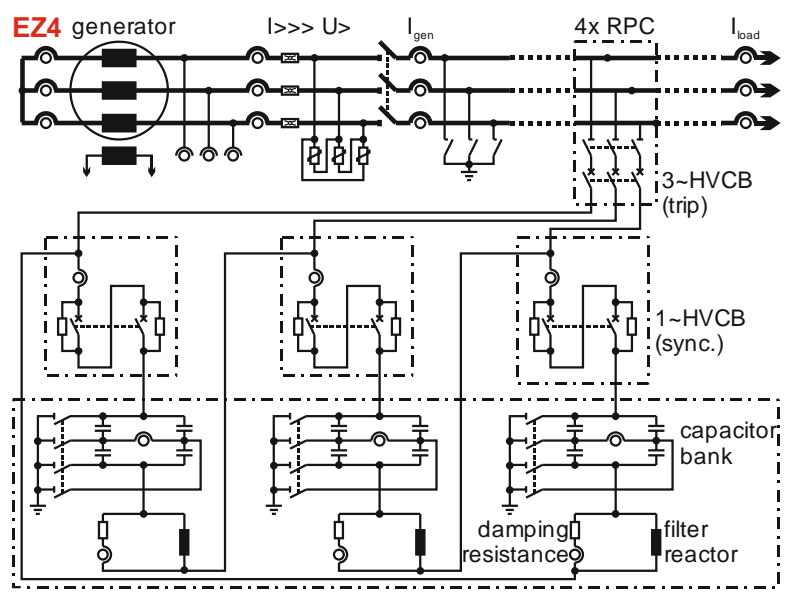

Fig. 5. Circuit diagram RPC module.

Each RPC module consists of a 3-phase capacitor bank. The RPC modules are choked. The air-cored filter reactors are tuned to a natural frequency of $339 \mathrm{~Hz}$. To avoid resonant excitation by harmonics from the converter loads at network frequencies $>105 \mathrm{~Hz}$, additional damping resistors were connected in parallel to the filter reactors. The main component parameters are given in Table 2.

\subsection{Control}

The complete control, interlock, fault evaluation and operating conditions are implemented in a Simatic S7. A Siemens Windows Control Center (WinCC) operator panel is used for both operation and visualization. The current switching sequence of the RPC modules is $15 \rightarrow$ $30 \rightarrow 30 \rightarrow 15$ Mvar. The sequence can be changed individually for generator EZ3 and EZ4 at the WinCC panel. The switching hysteresis is $+10 /-8$ Mvar. Both 15 resp. 30 Mvar modules of a generator will be used alternately. If a step of the sequence is not possible (e.g. no appropriate module available), the next step will be selected. The programmed delay time is $20 \mathrm{~ms}$ for both directions. The offset avoids over-compensation during switch-off. Due to the discharge time constant of the capacitors each module can only be used once during a plasma pulse. In order to minimize network disturbances, synchronous switching of the RPC modules close to the voltage zero crossing of every single phase is required. A test mode can be selected at the WinCC panel for commissioning. In this mode the phase-synchronized switching of every RPC module can be checked by pressing an "on" / "off” button.

\subsection{Protection}

The $10 \mathrm{kV}$ switchgear is equipped with timeovercurrent protection relays including short circuit protection. To detect faulty capacitors each capacitor bank is split into two half-modules (H-segmentation; see Fig. 5). An unbalance protection relay connected to a CT in the shunt arm monitors the symmetry between the half-modules. For overcurrent protection of the damping resistors additional CTs are mounted in each phase of an RPC module. Finally the line voltage is monitored. In case of a failure the 3-phase HVCB will be tripped. Every fault is indicated at the WinCC operator panel.

\section{Installation and commissioning}

\subsection{Installation}

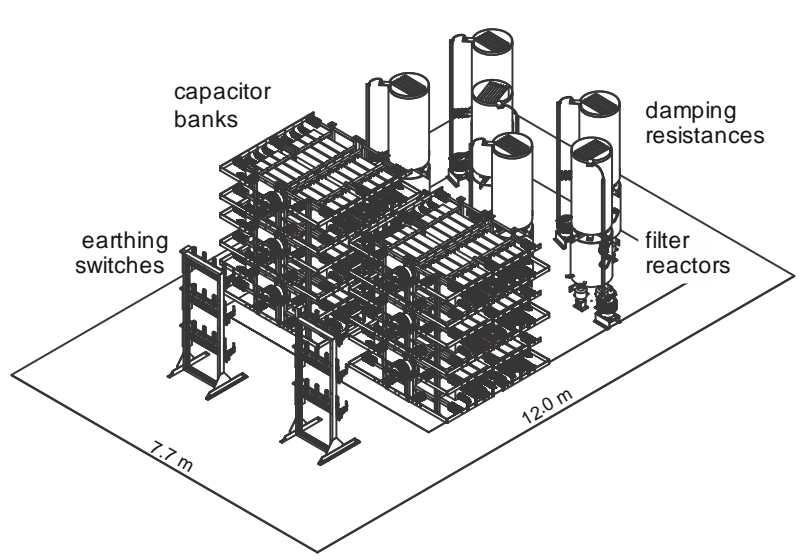

Fig. 6. Layout of 30 Mvar RPC modules M5 and M6.

The $10 \mathrm{kV}$ switchboards for the EZ4 compensation have been selected taking into consideration the necessary power cable connections to the EZ4 busbar system. Modules 3 and 4 were located best for the first step using 2x 15 Mvar modules from EZ3. In a second step the old 15 Mvar RPC modules 5/7 and 6/8 have been paralleled in order to build the two $30 \mathrm{Mvar}$ modules 7 and 8 for generator EZ3. The third step was to purchase two new 30 Mvar modules 5 and 6 for generator EZ4 (see Table 1). In order to place the 
additional modules a third floor was built on top of the existing RPC building. The layout of the new installation is shown in Fig. 6. For operating the EZ3 and EZ4 compensations independently, the auxiliary power supplies, PLC control and hard wired interlocks of the RPC units had to be split up.

\subsection{Commissioning}

By help of the "test mode" were the RPC modules proved with the generator running at no-load. The results are indicated in Fig. 7 and 8. All components behave as expected. Small voltage rises are quickly compensated.

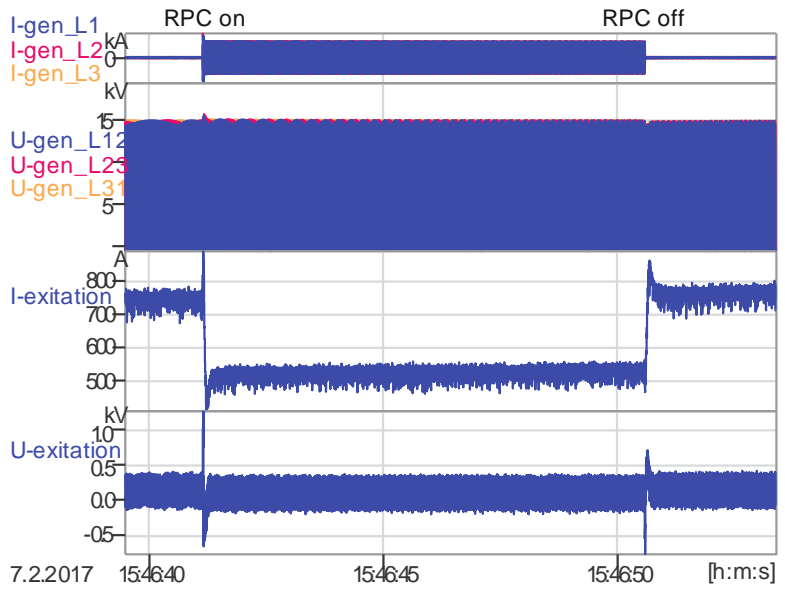

Fig. 7. Switching test of a 30 Mvar RPC module.

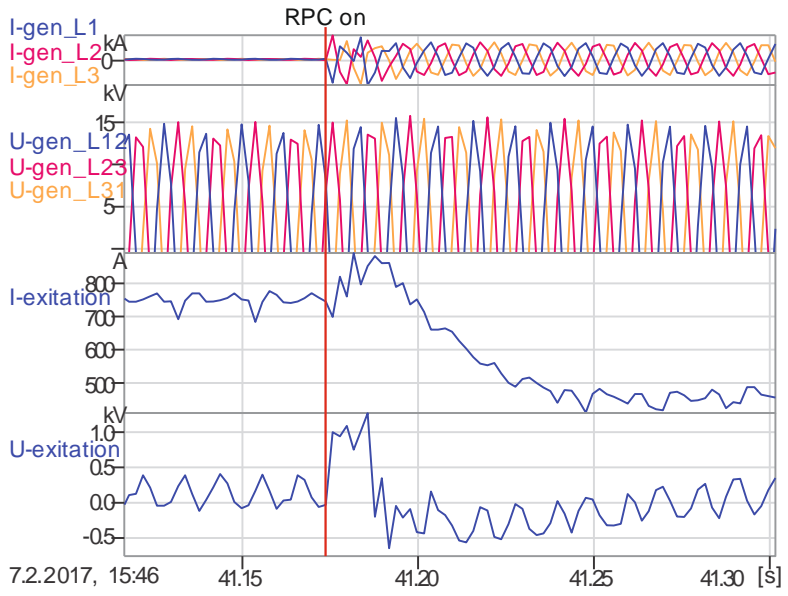

Fig. 8. Transient behavior during RPC switching.

\section{Operational experience}

Regular operation of the EZ4 reactive power compensation started in March 2017. The operational results are discussed for AUG plasma discharge \#33.945 as shown in Fig. 9. Most significant is the reduction of the generator apparent and reactive power compared to the load power and thus the reduction of the current load and warming up of the generator stator winding. The resulting $\mathrm{I}^{2} \mathrm{t}$ drops from $750 \mathrm{kA}^{2} \mathrm{~S}$ to $250 \mathrm{kA}^{2} \mathrm{~S}$. The mechanical stress on the generator - corresponding to the active power - stays the same and the apparent generator power is close to the limit. The possible speed range - corresponding to the energy available - is not completely used. Therefore longer plasma pulses will be possible.

\section{Conclusion}

The extended reactive power compensation for generators EZ3 and EZ4 operates very effective and reliable with 2x 15 Mvar and 2x 30 Mvar RPC modules each. The $I^{2} t$ corresponding to the thermal load of the generator stator winding drops significantly. Since the available energy of the flywheel is not completely used yet, longer AUG plasma pulses will be possible in the future towards achieving a stationary behavior of the current profile and plasma wall interaction under reactor relevant conditions. Further on a more efficient operation close to the limits of the systems is possible.

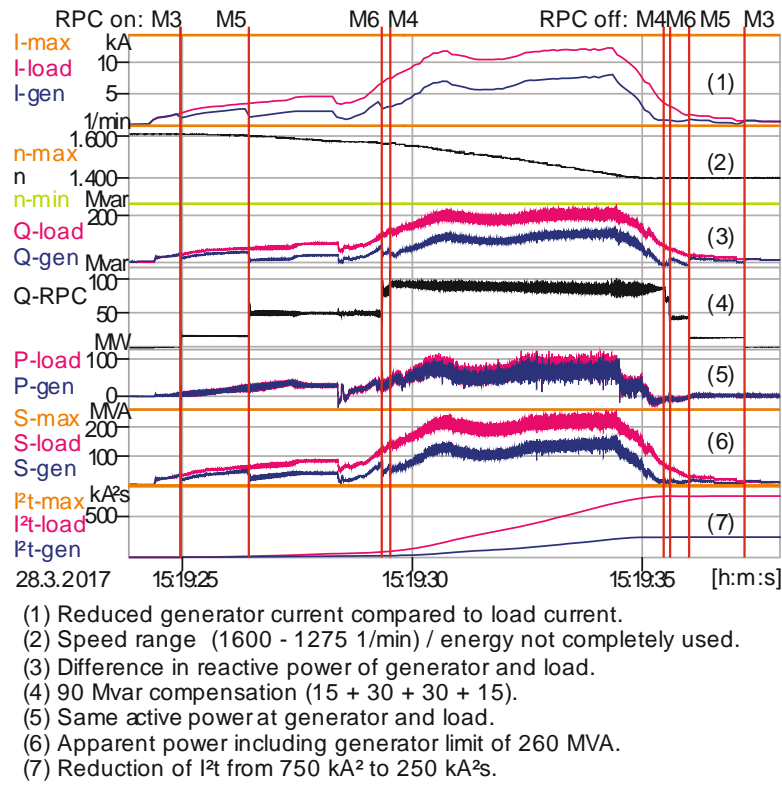

Fig. 9. EZ4 RPC operation at AUG discharge \#33.945

\section{Acknowledgements}

This work has been carried out within the framework of the EUROfusion Consortium and has received funding from the Euratom research and training programme 2014-2018 and 2019-2020 under grant agreement No 633053. The views and opinions expressed herein do not necessarily reflect those of the European Commission.

\section{References}

[1] C.-P. Käsemann, E. Grois, F. Stobbe, M. Rott, K. Klaster, ASDEX Upgrade Team, Pulsed Power Supply System of the ASDEX Upgrade Tokamak Research Facility, 2015, https://doi.org/10.1109/EEEIC.2015.7165545.

[2] C.-P. Käsemann, A. Kallenbach, J. Stober, J.-M. Noterdaeme, C. Hopf, N. Arden, I. Goldstein, ASDEX Upgrade Team, Extension of Heating and Pulse Power Capabilities at ASDEX Upgrade, 2017, https://doi.org/10.1016/j.fusengdes.2017.05.035.

[3] C. Sihler, B. Streibl, R. Klein, W. Schlüter, M. Krohn, Reactive power compensation for the pulsed power supply of ASDEX Upgrade, Fusion Technol (1998) 887-890

[4] C. Sihler, M. Huart, C.-P. Käsemann, B. Streibl, ASDEX Upgrade Team, Operational Experience with Reactive Power Control Methods Optimized for Tokamak Power Supplies, 2003, https://doi.org/10.1016/S0920-3796(03)002874.

[5] H. Mrugowsky, Drehstrommaschinen im Inselbetrieb, 2013, DOI 10.1007/978-3-8348-2136-2 